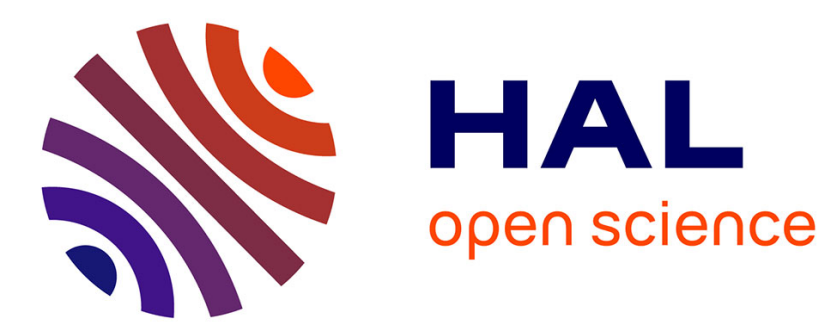

\title{
Model predictive control of free surfactant concentration in emulsion polymerization
}

\author{
Bruno da Silva, Pascal Dufour, Nida Sheibat-Othman, Sami Othman
}

\section{To cite this version:}

Bruno da Silva, Pascal Dufour, Nida Sheibat-Othman, Sami Othman. Model predictive control of free surfactant concentration in emulsion polymerization. International Federation of Automatic Control (IFAC) World Congress, Jul 2008, Seoul, South Korea. paper 1693, pp. 8375-8380, 10.3182/200807065-KR-1001.1693 . hal-00352737v2

\section{HAL Id: hal-00352737 https://hal.science/hal-00352737v2}

Submitted on 22 Jan 2009

HAL is a multi-disciplinary open access archive for the deposit and dissemination of scientific research documents, whether they are published or not. The documents may come from teaching and research institutions in France or abroad, or from public or private research centers.
L'archive ouverte pluridisciplinaire HAL, est destinée au dépôt et à la diffusion de documents scientifiques de niveau recherche, publiés ou non, émanant des établissements d'enseignement et de recherche français ou étrangers, des laboratoires publics ou privés. 
This document must be cited according to its final version which is published in a conference proceeding as:

B. Da Silva ${ }^{1}$, P. Dufour ${ }^{1}$, N. Othman ${ }^{1}$, S. Othman ${ }^{1}$, « Model predictive control of free surfactant concentration in emulsion polymerization »,

Proceedings of the 17th IFAC World Congress 2008, Paper 1693, pp. 8375-8380, Seoul, South Korea, July 6-11, 2008 http://dx.doi.org/10.3182/20080706-5-KR-1001.1693

All open archive documents of Pascal Dufour are available at: http://hal.archives-ouvertes.fr/DUFOUR-PASCAL-C-3926-2008

The professional web page ( $\mathrm{Fr} / \mathrm{En}$ ) of Pascal Dufour is: http://www.lagep.univ-lyon1.fr/signatures/dufour.pascal

1

Université de Lyon, Lyon, F-69003, France; Université Lyon 1;

CNRS UMR 5007 LAGEP (Laboratoire d'Automatique et de GEnie des Procédés),

43 bd du 11 novembre, 69100 Villeurbanne, France

Tel +33 (0) 472431845 - Fax +33 (0) 472431699

http://www-lagep.univ-lyon1.fr/ http://www.univ-lyon1.fr http://www.cnrs.fr 


\title{
Model Predictive Control of Free Surfactant Concentration in Emulsion Polymerization
}

\author{
Bruno da Silva, Pascal Dufour ${ }^{1}$ \\ Nida Sheibat-Othman and Sami Othman \\ Université de Lyon, Lyon, F-69003, France ; Université Lyon 1 ; \\ CNRS UMR 5007 LAGEP (Laboratory of Process Control and \\ Chemical Engineering), 43 bd du 11 novembre, 69100 Villeurbanne, \\ France
}

\begin{abstract}
In emulsion polymerization processes, the surfactant concentration plays an important role in the latex stability, reaction kinetics and particle size distribution (PSD). Controlling the free surfactant concentration in the aqueous phase ensures the stability of the latex and the control of the micellar nucleation rate. The PSD is determined by particle nucleation, growth and stability which are highly nonlinear behaviors. The PSD affects the polymer rheology, adhesion, optical properties and mechanical strength. This work deals with the model predictive control (MPC) of free surfactant concentration using the surfactant feed rate as a control variable. The used strategy is a global method that aims to reduce the on-line calculation time due to the partial differential equations (PDE) model based optimization task resolution. In order to decrease the computational burden, the nonlinear PDE system is solved off-line. Then, a linearized PDE model around the previous off-line behavior is used to find the optimal variations for the on-line predictive control.
\end{abstract}

Keywords: Control of distributed systems; Model predictive and optimization-based control; Process control applications.

\section{INTRODUCTION}

The main objective of this paper is to apply MPC to emulsion polymerization processes modeled by nonlinear partial distributed equations. Semino and Ray (1995) have studied the formal controlability of emulsion polymerization described by population balance equations (PBE) and employed the feed concentrations of surfactant, initiator, inhibitor to control the PSD.In the literature, few results have been published for the close loop control of PSD where its dynamic is governed by population balance equations. Many works, Crowley et al. (2000), Immanuel and Doyle III (2002) and Zeaiter et al. (2002) used an open loop model optimization to attain a final target PSD . The calculation of optimal control trajectories is done off line. Flores-Cerillo and MacGregor (2002) addressed the control of the PSD, using available on-line measurement (temperature) and off-line measurement (PSD) to predict the final PSD and, if necessary, to compute mid-course corrections. Doyle III et al. (2003) proposed a hybrid model based approach for batch-to-batch control of PSD. On-line measurement of the full PSD was assumed available which is still a challenging issue. Wang and Doyle III (2004) proposed a reachability analysis of systems described by PBE and pointed out the importance of proper initial reaction conditions, and in the case of midcourse correction the importance of early PSD measurements, with proper

\footnotetext{
1 Corresponding author: Pascal Dufour, Fax: 33-4.72.43.16.99, Email: dufour@lagep.univ-lyon1.fr
}

early corrective action. Zeaiter et al. (2006) implemented a MPC strategy for a single input single output (SISO) case for PSD control with monomer flow rate manipulation and investigated a multiple input multiple output (MIMO) control of PSD and molecular-weight distribution (MWD) simultaneously where the monomer flow rate and reactor temperature are manipulated variables.

In practice, sensors used to measure the PSD usually require sampling, dilution and analysis. Due to this difficult and time consuming analysis, usualy soft sensors or open loop model based observers were employed. Santos Jr. et al. (2007) used the conductivity measurements and ion-selective electrodes to monitor the free surfactant molecules during anionic (sodium dodecyl sulfate) stabilized emulsion polymerization. This information would provide information about the particle stabilization and the rate of nucleation which gives an alternative measurement to control the PSD.

In this study, we consider model predictive control of the free surfactant concentration in the aqueous phase, using the surfactant flow rate as a constrained manipulated variable. Controlling the free surfactant in the aqueous medium may ensure the stability of latex, and the dispersity of the distribution by controlling the micellar nucleation. In the first part of this paper, the dynamic model of emulsion polymerization is adapted. Secondly, the control strategy applied in Dufour et al. (2003) for PDE systems 
to reduce the on-line resolution time is employed. Finally, simulation results are discussed.

\section{STYRENE EMULSION POLYMERIZATION MODEL}

In emulsion polymerization, the PSD can be described by two types of models. The first model is the pseudo-bulk model that is available for large particles in which more than one free radical can co-exist in a same particle for a significant period, Immanuel and Doyle III (2002). The second model is the 0-1 model. It was used by Coen et al. (1998) to model coagulation and secondary nucleation. This model is adapted only for systems with the number of radicals per particle equal to 0 or 1 . Therefore, this model is generally available for small particles. It distinguishes particles who have a polymeric radical $\left(n_{1 p}\right)$, particles who have no radicals $\left(n_{0}\right)$ and particles who have a monomeric radical $\left(n_{1 m}\right)$.

\section{$2.10-1$ model}

Models describing the process kinetics and particle evolution for the 0-1 system is given in detail in Crowley et al. (2000).

$$
\left\{\begin{aligned}
\frac{\partial n_{0}(r, t)}{\partial t}= & \rho(r)\left(n_{1 p}(r)+n_{1 m}(r)-n_{0}(r)\right) \\
& +k_{0}(r) n_{1 m}(r) \\
\frac{\partial n_{1 p}(r, t)}{\partial t}= & -\left(\rho(r)+k_{t r}[M]_{p}\right) n_{1 p}(r)+\rho_{r}(r) n_{0}(r) \\
& +k_{p e}[M]_{p} n_{1 m}(r)-\frac{\partial\left[G(r) n_{1 p}(r)\right]}{\partial r} \\
\frac{\partial n_{1 m}(r, t)}{\partial t}= & \rho_{m}(r) n_{0}(r)+k_{t r}[M]_{p} n_{1 p}(r) \\
& -n_{1 m}(r)\left(\rho(r)+k_{p e}[M]_{p}+k_{0}(r)\right)
\end{aligned}\right.
$$

where $[M]_{P}$ is the monomer concentration in particles, $k_{t r}$ is the coefficient of transfer to monomer in the polymer particle, $k_{p e}$ is the propagation coefficient of monomeric radicals in particles, $\rho(r, t)=\rho_{r}(r, t)+\rho_{m}(r, t)$ represents the overall rate of radical entry into particles with:

$$
\left\{\begin{array}{l}
\rho_{r}(r)=\sum_{i=z}^{j_{c r i t-1}} k_{e, i}(r)\left[I M_{i}\right] \\
\rho_{m}(r)=k_{e E}(r)[E]
\end{array}\right.
$$

$\left[I M_{i}\right]$ is the concentration of oligomeric radicals of degree $i$ in the aqueous phase, $[E]$ is the concentration of monomeric radicals that can desorb out of particles, $z$ is the critical chain length at which polymer particles can enter into polymer radicals or micelles (micellar nucleation), $j_{\text {crit }}$ is the chain length at which the radicals become insoluble in water and precipitate forming new particles (homogeneous nucleation).

Rate coefficients of monomer radicals entry into particles $k_{e E}$, oligomer radicals entry into particles $k_{e, i}$, radicals entry into micelles $k_{e m, i}$ and radicals desorption from particles $k_{0}$ are governed by the diffusion coefficient $D_{w}$ and depend on the particle radius $r$.
The total number of particles of size between $r$ and $r+d r$ is given by:

$$
n(r, t)=n_{0}(r, t)+n_{1 p}(r, t)+n_{1 m}(r, t)
$$

The average number of radicals in particles of size $r$ at time $t, \bar{n}(r, t)$ is given by:

$$
\bar{n}(r, t)=\frac{n_{1 p}(r, t)+n_{1 m}(r, t)}{n(r, t)}
$$

Particle growth rate is given by:

$$
G(r)=\frac{k_{p}[M]_{P} M W_{m}}{4 \pi r^{2} d_{p} N_{A}}
$$

with $k_{p}$ the monomer propagation rate coefficient into particles, $M W_{m}$ the molecular weight of monomer, $d_{p}$ the density of polymer and $N_{A}$ Avogadro's number.

Both homogeneous and micellar nucleations are considered. The total nucleation rate $\left(\Re_{n u c}=\Re_{n u c}^{\text {hom }}+\Re_{n u c}^{\text {mic }}\right)$ acts as a boundary condition of (1):

$$
n_{1 p}\left(r_{n u c}, t\right)=\frac{\Re_{n u c}(t)}{G\left(r_{n u c}\right)}
$$

where $G\left(r_{n u c}\right)$ is the growth rate of particles of size $r_{n u c}$ and

$$
\left\{\begin{array}{l}
\Re_{n u c}^{\text {hom }}=k_{p,\left(j_{\text {crit }}-1\right)}^{a q}[M]_{a q}\left[I M_{j_{c r i t}-1}\right] v^{a q} \\
\Re_{n u c}^{m i c}=\sum_{i=z}^{j_{c r i t}-1} k_{e m, i}[M i c]\left[I M_{i}\right] v^{a q}
\end{array}\right.
$$

with $[M]_{a q}$ the monomer concentration in the aqueous phase, $[M i c]$ the concentration of micelles, $k_{p, i}^{a q}$ the coefficient of propagation of monomer with radical on length $\mathrm{i}, r_{n u c}$ the nucleation radius and $v_{a q}$ the aqueous phase volume.

\subsection{Monomer material balance}

The residual amount of monomer is given by:

$$
\frac{d N_{m}}{d t}=Q_{m}-k_{p}[M]_{P} \int_{r_{n u c}}^{\infty} \bar{n}(r, t) n(r, t) d r
$$

where $N_{m}$ is the number of moles of residual monomer and $Q_{m}$ is the monomer flow rate.

\subsection{Surfactant material balances}

The number of moles of surfactant introduced into the reactor is given by:

$$
\frac{d N_{S}}{d t}=Q_{S}
$$

where $Q_{S}$ is the flow rate of surfactant. The concentration of free surfactant in the aqueous phase $\left[S_{a q}\right]$ can be calculated from the following equation:

$$
\left[S^{a q}\right] v^{a q}=N_{S}-N_{S}^{P}-N_{S}^{d}
$$

where $N_{S}^{P}$ and $N_{S}^{d}$ are the number of moles of surfactant adsorbed on the surface of particles and droplets respectively:

$$
N_{S}^{d}=\frac{3 V^{d}}{a_{s d} r_{d} N_{A}}
$$


$V^{d}$ is the droplets volume, $a_{s d}$ is the surface area of droplets covered by a single surfactant molecule and $r d$ is the radius of the monomer droplets.

$$
N_{S}^{P}=\frac{S_{\text {par }}}{N_{A} A_{S}}
$$

$S_{\text {par }}$ is the total particle surface:

$$
S_{\text {par }}=4 \pi N_{A} \int_{r_{n u c}}^{\infty} n(r) r^{2} d r
$$

$A_{s}$ is the minimum area occupied by a single surfactant molecule:

$$
A_{s}=a_{s p}\left(1+\frac{1}{\left[S^{a q}\right] b_{s}}\right)
$$

where $a_{s p}$ is the surface area of particles covered by a single surfactant molecule and $b_{s}$ is the Langmuir adsorption isotherm parameter.

The concentration of micelles is given by:

$$
[M i c]=\max \left(0, \frac{\left[S^{a q}\right]-C M C}{n_{a g g}}\right)
$$

where $C M C$ is the critical micellar concentration and $n_{a g g}$ is the aggregation number for the surfactant.

\subsection{Aqueous phase reactions}

The polymerization process starts by the initiator decomposition $(I)$ in the aqueous phase producing primary radicals $\left(I^{\bullet}\right)$ that react with monomer molecules to generate oligomeric radicals $\left(I M_{i}\right)$.

The material balances of the species in the aqueous phase are given by:

$$
\begin{aligned}
& \frac{1}{v^{a q}} \frac{d\left([I] v^{a q}\right)}{d t}=\frac{Q_{I}}{v^{a q}}-k_{d}[I] \\
& \frac{1}{v^{a q}} \frac{\left(d\left[I^{\bullet}\right] v^{a q}\right)}{d t}=2 k_{d}[I]-\left(k_{p I}^{a q}[M]_{a q}+k_{t}^{a q}[T]\right)\left[I^{\bullet}\right] \\
& \frac{1}{v^{a q}} \frac{d\left(\left[I M_{1}\right] v^{a q}\right)}{d t}=k_{p I}^{a q}[M]_{a q}\left[I^{\bullet}\right]
\end{aligned}
$$

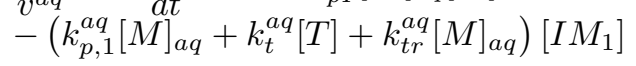

$$
\begin{aligned}
& \frac{1}{v^{a q}} \frac{d\left(\left[I M_{i}\right] v^{a q}\right)}{d t}=k_{p, i-1}^{a q}[M]_{a q}\left[I M_{i-1}\right] \\
& -\left(k_{p, i}^{a q}[M]_{a q}+k_{t}^{a q}[T]+k_{t r}^{a q}[M]_{a q}\right)\left[I M_{i}\right], \quad i=2, z-1 \\
& \frac{1}{v^{a q}} \frac{d\left(\left[I M_{i}\right] v^{a q}\right)}{d t}=k_{p, i-1}^{a q}[M]_{a q}\left[I M_{i-1}\right] \\
& v^{v^{a q}}\left(k_{p, i}^{a q}[M]_{a q}+k_{t}^{a q}[T]+k_{t r}^{a q}[M]_{a q}+k_{e m, i}[M i c]\right)\left[I M_{i}\right] \\
& -\frac{1}{v^{a q}} \int_{r_{n u c}}^{\infty} k_{e, i} n(r) d r\left[I M_{i}\right], \quad i=z, j_{c r i t}-1 \\
& \frac{1}{v^{a q}} \frac{d\left([E] v^{a q}\right)}{d t}=\frac{1}{v^{a q}} \int_{r_{n u c}}^{\infty} k_{0}(r) n_{1 m}(r) d r+k_{t r}^{a q}[M]_{a q}[T] \\
& -\frac{1}{v^{a q}} \int_{r_{n u c}}^{\infty} k_{e E}(r)[E] n(r) d r-k_{t}^{a q}[E][T]
\end{aligned}
$$

where $k_{d}$ is the coefficient of initiator decomposition, $k_{t}^{a q}$ is the coefficient of termination in the aqueous phase, $k_{t r}^{a q}$ is the coefficient of transfer to monomer in the aqueous phase, $Q_{I}$ is the initiator flow rate, $[I]$ is the initiator concentration, $[T]$ is the total concentration of radicals in the aqueous phase: $[T]=\sum_{i=1}^{j_{\text {crit-1 }}}\left[I M_{i}\right]+[E]+\left[I^{\bullet}\right]$.

\subsection{Bulk-like model}

Edouard et al. (2005) have written the 0-1 model under a new form, the bulk-like model. The state represents the total number of particles of size $r(n(r))$ for the 0-1 system and does not distinguish particles as a function of the number of radicals they contain $\left(n_{1 p}(r), n_{1 m}(r), n_{0}(r)\right)$. This allows the process output to become a part of the state of the model if a sensor is used to measure the particle size from time to time.

The model is developed using system (1). With the following change of variables $\left(N(r, t)=n_{1 p}(r, t)+n_{1 m}(r, t)\right)$ we obtain:

$$
\bar{n}(r, t)=\frac{N(r, t)}{n(r, t)}
$$

Taking the sum of the three equations in the 0-1 model (1) and assuming that the growth of the particles $n_{1 m}$ is not negligible gives a balance on the total number of particles in the reactor:

$$
\frac{\partial n(r, t)}{\partial t}=-\frac{\partial[G(r) \bar{n}(r, t) n(r, t)]}{\partial r}
$$

and the following equation can be obtained for $\bar{n}(r, t)$ by deriving equation(17) with respect to time:

$$
\frac{\partial \bar{n}(r, t)}{\partial t}=\frac{n(r, t) \frac{\partial N(r, t)}{\partial t}-N(r, t) \frac{\partial n(r, t)}{\partial t}}{n^{2}(r, t)}
$$

The quasi-steady state assumption for $n_{1 m}(r, t)$ Crowley et al. (2000) gives:

$$
\begin{aligned}
n_{1 m}(r, t)= & \frac{\rho_{m}(1-\bar{n}) n}{\rho+[M]_{P}\left(k_{p e}+k_{t r}\right)+k_{0}} \\
& +\frac{k_{t r}[M]_{P} \bar{n} n}{\rho+[M]_{P}\left(k_{p e}+k_{t r}\right)+k_{0}}
\end{aligned}
$$

We obtain the following model (bulk-like model) representing the PSD of a $0-1$ system:

$$
\left\{\begin{aligned}
\frac{\partial n(r, t)}{\partial t}= & -\frac{\partial[G(r) \bar{n}(r) n(r)]}{\partial r} \\
\frac{\partial \bar{n}(r, t)}{\partial t}= & \rho(r)(1-2 \bar{n}(r))-k_{0}(r) \frac{n_{1 m}(r)}{n(r)^{2}} \\
& +\frac{\partial[G(r) \bar{n}(r) n(r)]}{\partial r}\left(\frac{\bar{n}(r)-1}{n(r)}\right)
\end{aligned}\right.
$$

with the boundary conditions:

$$
\left\{\begin{array}{l}
n\left(r_{n u c}, t\right)=\frac{\Re_{n u c}(t)}{G\left(r_{n u c}\right)} \\
\bar{n}\left(r_{n u c}, t\right)=1
\end{array}\right.
$$




\section{MPC AND EMULSION POLYMERIZATION}

MPC is employed in a wide variety of real-time control applications, including chemical engineering, Qin and Badgwell (2003). At each sample time, with the update of new process measurements, an open-loop optimization over a finite prediction horizon aims to find the sequence of manipulated variables, which guarantees optimum process operation with robustness to operating conditions and model uncertainties. But few MPC studies are devoted to processes involving complexity of chemical properties and PDE models which describe such systems. In this work, the MPC strategy proposed by Dufour et al. (2003) is used. The control structure is an adaptation of MPC with internal model control (IMC) structure where the nonlinear PDE system (solved off-line) and a linearized PDE system (solved on-line) are both used to decrease the computational burden. The control strategy is concerned with on-line resolution that aims to correct off-line structure results. A similar control structure is applied by Zeaiter et al. (2006), considering step-response coefficients updated at every sequence and a disturbance term. The disturbance term correspond to the disturbance due to plant/model mismatch and the disturbance due to nonlinearities $\left(d^{n l}\right)$. The term $d^{n l}$ is determined at every sampling time by minimizing the output prediction error between the linear and non-linear models.

\subsection{MPC strategy}

The control problem is a general optimization problem over a receding horizon $N_{p}$ where $J$ is the cost function according to the desired objective, trajectory tracking in this study. This performance index can be written:

$$
J(p)=\sum_{j=k+1}^{k+N_{p}} g\left(y_{r e f}(j), y_{m}(j), u(j-1), e(k)\right)
$$

where $\mathrm{k}$ (resp. $\mathrm{j}$ ) is the actual (resp. future) discrete time index, $y_{r e f}$ describes the specified constrained behavior for the process output $y_{p}, y_{m}$ is the continuous model output and the error $e(j)$ is assumed constant (updated at each $k)$ in the future: $e(j)=e(k)=y_{p}(k)-y_{m}(k)$.

In order to take into account constraints on the manipulated variables, the transformation method for variables allows translating explicit magnitude and velocity constraints on the optimization argument $u$ as a new unconstrained argument $p$, Fletcher (1987).

$$
\left\{\begin{array}{l}
u(j)=f(p(j))=f_{\text {moy }}+f_{\text {amp }} \tanh \left(\frac{p(j)-f_{\text {moy }}}{f_{\text {amp }}}\right) \\
f_{\text {moy }}=\frac{f_{\text {max }}-f_{\text {min }}}{2} \\
f_{\text {amp }}=\frac{f_{\text {max }}+f_{\text {min }}}{2} \\
f_{\text {min }}=\max \left(u_{\min }, u(j-1)+\Delta u_{\min }\right) \\
f_{\text {max }}=\min \left(u_{\text {max }}, u(j-1)+\Delta u_{\max }\right)
\end{array}\right.
$$

Consequently, the penalized problem can be solved by any unconstrained optimization algorithm: the well-known and robust Levenberg-Marquardt's algorithm is used.

The nonlinear PDE model is discretized using the finite differences giving a finite nonlinear model $\left(S_{0}\right)$. The nonlinear PDE system is linearized giving a time-varying linearized model $\left(S_{T V L}\right)$. To decrease the on-line computational time, the nonlinear algebraic differential equations are solved off-line $\left(S_{0}\right)$ and the $\left(S_{T V L}\right)$ is solved on-line. These models are used on the following MPC linearized IMC-MPC structure:

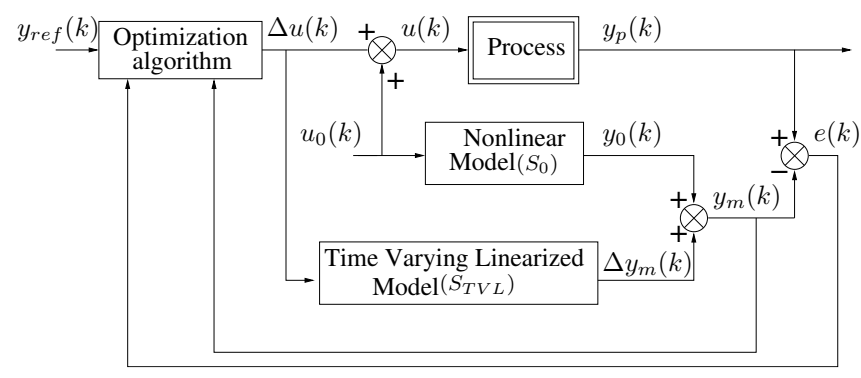

Fig. 1. General linearized IMC-MPC structure

\subsection{Model building for PSD prediction}

The considered model for the $\left(S_{0}\right)$ trajectories is given in section 2.5 , but only intervals I-II are considered, droplets of monomer are present during all the run. Consequently, $[M]_{p}$ and $[M]_{a q}$ are constant. Also, according to the model complexity, it was interesting to consider a simplified model for the on-line computation. Terms in the $\bar{n}(r, t)$ expression (21) which do not influence the overall dynamic $\left(S_{0}+S_{T V L}\right)$ are neglected which leads to:

$$
\left\{\begin{array}{l}
\frac{\partial n(r, t)}{\partial t}=-\frac{\partial[G(r) \bar{n}(r) n(r)]}{\partial r} \\
\frac{\partial \bar{n}(r, t)}{\partial t}=\frac{\partial[G(r) \bar{n}(r) n(r)]}{\partial r}\left(\frac{\bar{n}(r)-1}{n(r)}\right)
\end{array}\right.
$$

\subsection{Control objective}

In terms of final quality, many latex products have enhanced properties due to bimodal PSD. Free surfactant concentration is the essential driving force for particle nucleation (micellar nucleation). Consequently, controlling the free surfactant concentration causes micellar nucleation and influence the final PSD. In micellar nucleation, a particle is formed by the entry of a radical into a micelle, which can occur only above the CMC of the surfactant. Moreover, controlling free surfactant concentration can ensure the latex stability. For this reason, we considered surfactant feed rate as a manipulated variable and free surfactant concentration in the aqueous phase as controlled variable. The SISO control problem considered here is the tracking of a reference trajectory $y_{r e f}(t)$ for the process free surfactant concentration, subject to magnitude input constraints on the surfactant flow rate.

$$
J(p)=\sum_{j=k+1}^{k+N_{p}}\left(y_{r e f}(j)-y_{m}(j)-e(k)\right)^{2}
$$

where $y_{m}(j)=y_{0}(j)+\Delta y_{m}(j), y_{0}$ is the nonlinear model trajectory output solved off-line and $\Delta y_{m}$ is the timevarying linearized model output computed on-line.

Using the link between free surfactant concentration and PSD, the choice of the reference trajectory depends on 
the final PSD objective. To create a new population, the output free surfactant concentration must be above the CMC. Whereas, in order to ensure the stability of the latex without creating new particles, the ouput must be below the CMC but close to the CMC in order to ensure saturation of particles with surfactant and to allow a rapid control of the nucleation rate at any moment.

\section{SIMULATION RESULTS}

The physical and kinetic parameters for styrene at $50^{\circ} \mathrm{C}$ are given by Edouard et al. (2005). The MPC strategy was run in the MATLAB environment using the MPC@CB ${ }^{2}$ software. The software allows realizing the MPC under constraints of a continuous process. The originality of this software is first the ease of its use for any continuous SISO or MIMO process, through the user files, synchronized by few standard files, see Abid et al. (2007) for a painting curing process and Daraoui et al. (2007) for a lyophilisation process. Test runs were performed for an ab initio emulsion homopolymerization of styrene with a 60 seconds sampling time. Results with the same initial conditions $\left(N_{i}(0)=\right.$ $\left.0.001 \mathrm{~mol}, N_{s}(0)=0.004 \mathrm{~mol}, N_{m}(0)=3.59 \mathrm{~mol}\right)$ and different objective trajectories are shown in figures 2 4. These three cases are focused on the design of the free surfactant concentration trajectory to obtain a final bimodal PSD. Employing the same initial conditions and the same trajectory references up to the 100th minute implies that the last peak of the PSD has the same size for the three cases at the end of the simulation.

It can be seen that the output value is very close to the reference trajectory. Moreover, the free surfactant concentration profile and the final PSD are closely dependent. Tracking the free surfactant concentration allows an indirect control of the PSD.

Figures 2 and figures 3 show that the choice of the reference trajectory of the free surfactant concentration directly influences the final PSD. The two runs are the same until the 280 th minute. In the first case (figures 2), the reference implies only one micellar nucleation at the beginning of the simulation and consequently a monomodal PSD. Whereas in the second case (figures 3), the choice of the output profile leads to a bimodal PSD, with a secondary nucleation. It should be outlined however that the choice of the free surfactant concentration trajectory to attain a bimodal distribution is not really evident. Figure 4 shows that the time between the two nucleations is very critical. When the second nucleation was started at 115 minutes, instead of having a bimodal distribution, the attained PSD was broadened. The desired PSD should be determined the application.

\section{CONCLUSION}

Controlling the free surfactant concentration is efficient for PSD on-line control. The design of the output trajectory allows an indirect control of the PSD. The proposed MPC strategy allows decreasing the computional burden during on-line control and offers good perspectives for PSD control. The control of the whole PSD (nucleation

2 University Claude Bernard Lyon 1 - EZUS. In order to use MPC@CB, please contact the author: dufour@lagep.univ-lyon1.fr
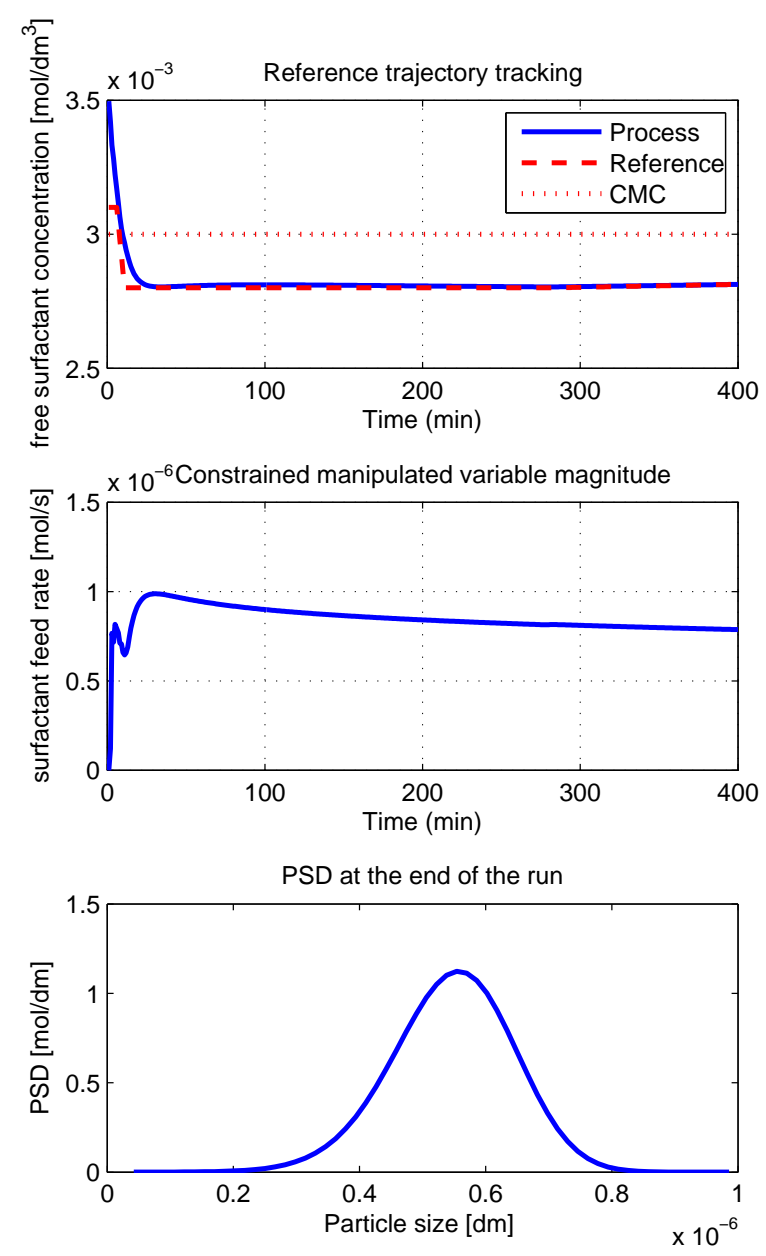

Fig. 2. Optimization by MPC of the dynamic of the output free surfactant concentration (run 1)

and growth), measuring both the PSD and the surfactant in the aqueous phase which leads to a MIMO control problem, is currently under study. Finally, this work is based on simulations and the experimental validation of this approach is under study.

\section{REFERENCES}

K. Abid, P. Dufour, I. Bombard, and P. Laurent. Model predictive control of a powder coating curing process: an application of the MPC@CB software. IEEE Chinese Control Conference, Zhangjiajie, China, 2:630634, 2007.

E.M. Coen, R.G. Gilbert, B. R. Morrison, H. Leube, and S. Peach. Modeling particle size distribution and secondary particle formation in emulsion polymerization. Polymer, 39(26):7099, 1998.

T.J. Crowley, E.S. Meadows, E. Kostoulas, and F.J. Doyle III. Control of particle size distribution described by a population balance of semibatch emulsion polymerization. Journal of Process Control, 10, 2000.

N. Daraoui, P. Dufour, and H. Hammouri. Model predictive control of the primary drying stage of a freeze drying of solutions in vials: An application of the MPC@CB 

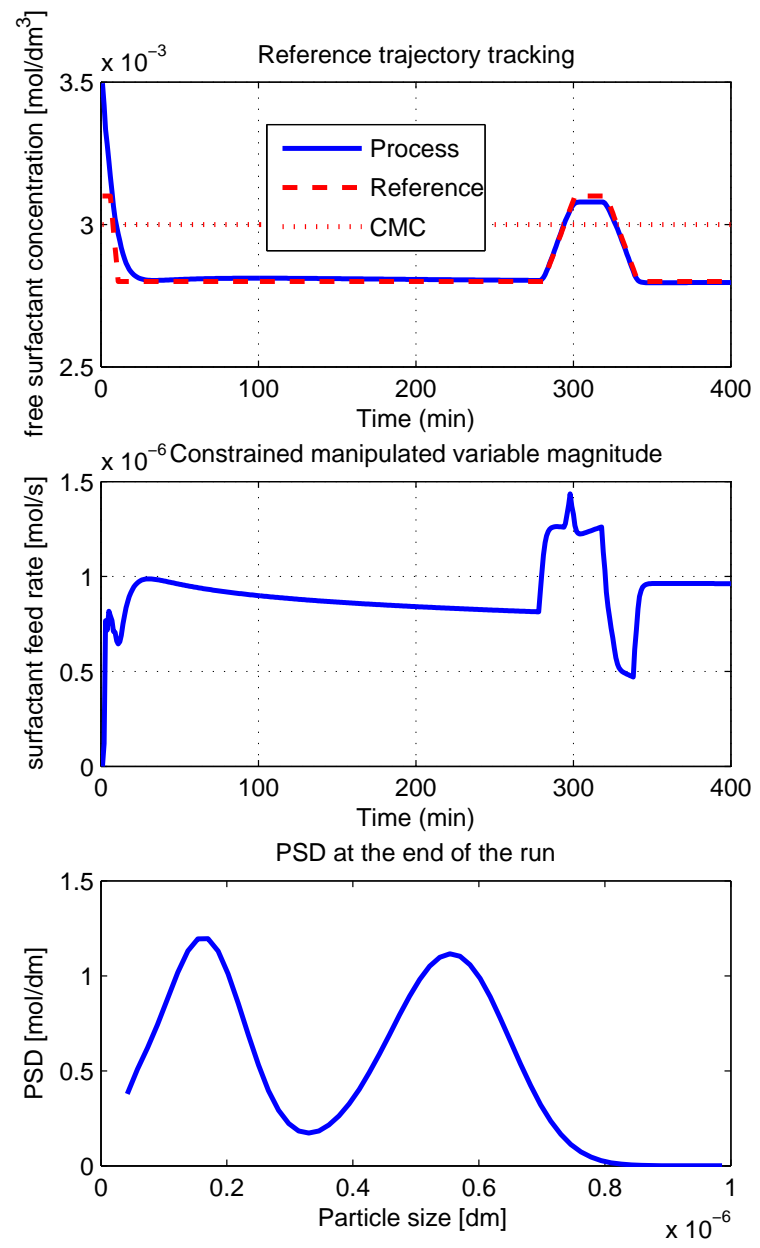

Fig. 3. Optimization by MPC of the dynamic of the output free surfactant concentration (run 2)

software (part1). 6th Asian Drying Conference, Hong Kong, China, 2:883-888, 2007.

F. J. Doyle III, C.A. Harrison, and T.J. Crowley. Hybrid model-based approach to batch-to-batch control of particle size distribution in emulsion polymerization. Computer and Chemical Engineering, 27:1153-1163, 2003.

P. Dufour, Y Touré, D. Blanc, and P. Laurent. On nonlinear distributed parameter model predictive control strategy : on-line calculation time reduction and application to an experimental drying process. Computer and Chemical Engineering, 27:1533-1542, 2003.

D. Edouard, N. Sheibat-Othman, and H. Hammouri. Observer design for particle size distribution in emulsion polymerisation. AIChE Journal, 51(12), 2005.

R. Fletcher. Pratical Methods of Optimization. John Wiley and Sons, 1987.

J. Flores-Cerillo and J. F. MacGregor. Control of particle size distributions in emulsion semibatch polymerization using mid-course correction policies. Industrial and Engineering Chemistry Research, 41:1805-1814, 2002.

C. D. Immanuel and F. J. Doyle III. Open-loop control of particle size distribution in semi-batch emulsion copolymerization using a genetic algorithm. Chemical Engineering Science, 57:4415-4427, 2002.
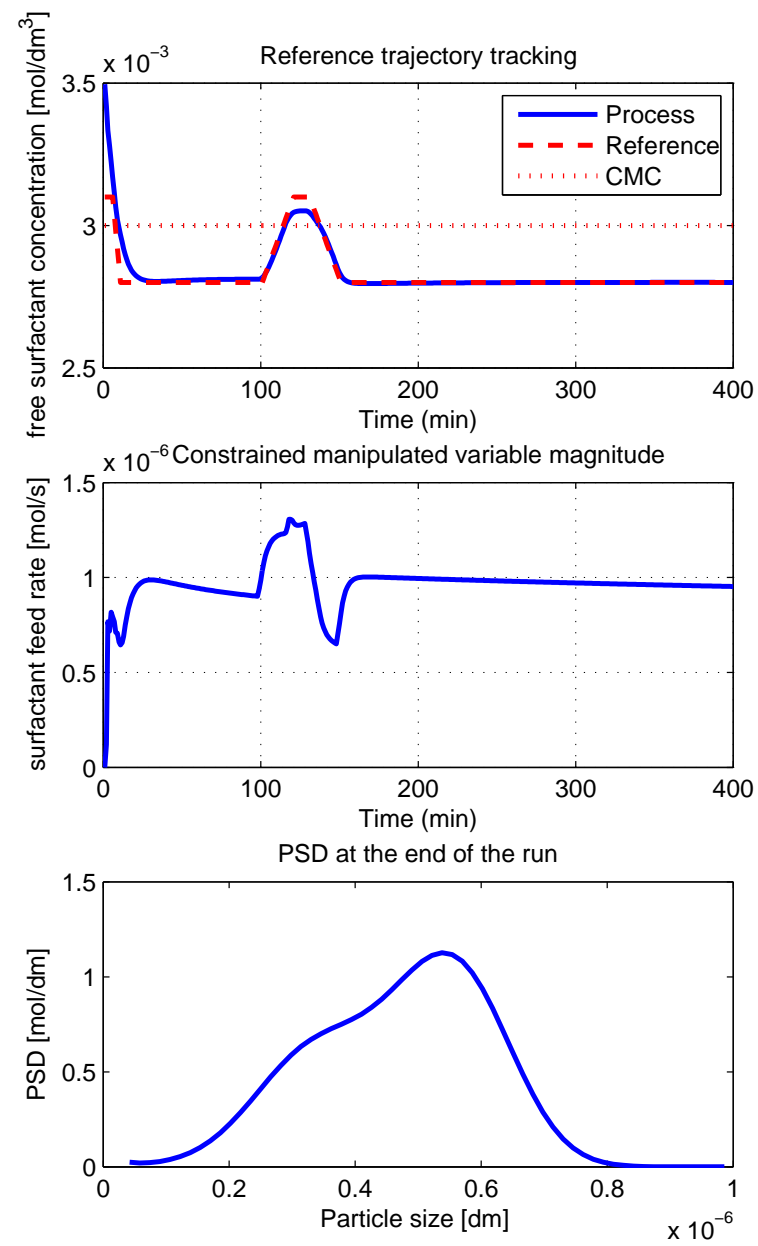

Fig. 4. Optimization by MPC of the dynamic of the output free surfactant concentration (run 3)

S.J. Qin and T.A. Badgwell. A survey of industrial model predictive control technology. Control Engineering Practice, pages 733-764, 2003.

G.P. Santos Jr., C. Martins, M. Fortuny, A.F. Santos, M. Turmine, C. Graillat, and T.F.L. McKenna. Inline and in situ monitoring of ionic surfactant dynamics in latex reactors using conductivity measurements and ion-selective electrodes. Ind. Eng. Chem. Res., 46:14651474, 2007.

D. Semino and W. H. Ray. Control of systems described by population balance equations-ii. emulsion polymerization with constrained control action. Chemical Engineering Science, 50:1825-1839, 1995.

Y. Wang and F. J. Doyle III. Reachibility of particle size distribution in semibatch emulsion polymerization. AIChE Journal, 50:1153-1163, 2004.

J. Zeaiter, J.A. Romagnoli, and V.G. Gomes. Operation of semi-batch emulsion polymerization reactors : Modelling, validation and effect of operating conditions. Chemical Engineering Science, 57:2955-2969, 2002.

J. Zeaiter, J.A. Romagnoli, and V.G. Gomes. Online control of molar mass and particle-size distributions in emulsion polymerization. AIChE, 52:1770-1779, 2006. 